\title{
La Vision de Tondale. Les versions françaises de Jean de Vignay, David Aubert, Regnaud le Queux, Éditées par Mattia Cavagna
}

\section{G. Matteo Roccati}

\section{(2) OpenEdition}

\section{Journals}

\section{Édition électronique}

URL : http://journals.openedition.org/studifrancesi/8190

DOI : 10.4000/studifrancesi.8190

ISSN : 2421-5856

Éditeur

Rosenberg \& Sellier

\section{Édition imprimée}

Date de publication : 1 mai 2009

Pagination : 152

ISSN : 0039-2944

\section{Référence électronique}

G. Matteo Roccati, «La Vision de Tondale. Les versions françaises de Jean de Vignay, David Aubert, Regnaud le Queux, Éditées par Mattia Cavagna », Studi Francesi [En ligne], 157 (LIII | I) | 2009, mis en ligne le 30 novembre 2015, consulté le 13 janvier 2021. URL : http://journals.openedition.org/ studifrancesi/8190; DOI : https://doi.org/10.4000/studifrancesi.8190

Ce document a été généré automatiquement le 13 janvier 2021.

\section{cc) (1) 8}

Studi Francesi è distribuita con Licenza Creative Commons Attribuzione - Non commerciale - Non opere derivate 4.0 Internazionale. 


\title{
La Vision de Tondale. Les versions françaises de Jean de Vignay, David Aubert, Regnaud le Queux, Éditées par Mattia Cavagna
}

\author{
G. Matteo Roccati
}

\section{RÉFÉRENCE}

La Vision de Tondale. Les versions françaises de Jean de Vignay, David Aubert, Regnaud le Queux, Éditées par Mattia CAVAGnA, Paris, Champion, 2008 ("Les Classiques Français du Moyen Âge", 159), pp. 352.

1 La Visio Tungdali (censée avoir eu lieu en 1149), a donné lieu à deux versions abrégées qui apparaissent dans le Speculum historiale de Vincent de Beauvais et dans le Speculum morale. Elle a connu une diffusion importante, notamment à travers les nombreuses traductions qui en ont été faites. Les trois versions contenues dans ce volume ont été choisies car elles étaient inédites, que leurs auteurs sont assez célèbres par ailleurs, et qu'elles ont été réalisées à partir des trois versions latines différentes.

2 L'introduction présente de manière synthétique le courant littéraire à l'intérieur duquel se situe le texte latin, les étapes que ce dernier a traversées et la réception de l'œuvre à la fin du Moyen Âge. L'édition de chaque version est précédée d'une introduction spécifique traitant des points suivants: auteur, texte source, notes sur la traduction, manuscrits et leur classement, étude linguistique, principes d'édition. Les variantes sont indiquées en bas de page et de copieuses notes critiques suivent les textes. Celui de Jean de Vignay (vers 1320-1330, pp. 65-109) est tiré du Miroir historial (onze témoins); celui de David Aubert (1475, pp. 161-221) est conservé dans un précieux manuscrit unique (Paul Getty Museum, ms. 30) réalisé pour Marguerite d'York, troisième femme de Charles le Téméraire: ce manuscrit est révélateur de la sensibilité 
de la commanditaire, liée à la devotio moderna, et de la manière dont le texte a été lu à la cour de Bourgogne. La traduction de Regnaud le Queux (1480, pp. 275-301) est extraite du Baratre infernal (trois témoins).

3 Le volume est complété par le glossaire (pp. 311-329), l'index des noms propres (pp. 331-333) et la bibliographie (pp. 335-350). 